condition which although apparently rare can have a significant effect on the quality of life of affected patients.

P. Ryan, London

1. Patel S, Choyee S, Uyanne J et al. Non-exposed bisphosphonate-related osteonecrosis of the jaw: a critical assessment of current definition, staging, and treatment guidelines. Oral Dis 2012; 18: 625-632.

2. Pichardo S E, Kuypers S C, van Merkesteyn J P. Denosumab osteonecrosis of the mandible: a new entity? A case report. J Craniomaxillofac Surg 2012; pii: S1010-5182(12)00229-6. doi: 10.1016/j. jcms.2012.10.014 [Epub ahead of print].

DOI: 10.1038/sj.bdj.2013.384

\section{BONE CRUSHING HABITS}

Sir, we are concerned about tooth wear in patients from African and AfroCaribbean origin and in particular the prevalence of a bone crushing habit as a risk factor for tooth wear. There is a cultural habit of crushing chicken and fish bones as part of their daily diet.

We prospectively audited 50 successive patients of African and AfroCaribbean origin aged between 20-50 years who were examined in a general dental practice in southeast London to determine the prevalence and symptoms of bone crushing. We found that $80 \%$ of the patients had a score of 2 or more on the Smith and Knight tooth wear index. Sixty-six percent indicated that they crush chicken and fish bones with their teeth. In $26 \%$ of the patients other risk factors such as teeth grinding and acid erosion were found. In 64\% of the patients tooth wear was not the presenting complaint. In 24\% the major presenting complaint was aesthetic concerns (short teeth), followed by 12\% with teeth sensitivity. Eighty-two percent were not aware that crushing bones is an important risk factor in tooth wear.

The association between tooth wear and bone crushing in patients from African and Afro-Caribbean origin has been known for years but the prevalence of the habit may have been underestimated. This audit demonstrates the high prevalence of tooth wear related to bone crushing. It is important that dentists educate patients and discourage them from bone crushing habits. Specific questions need to be asked when taking a history from patients about their dietary habits and specifically about bone crushing. One important consequence of this problem is an asso- ciation with failure of prosthodontic and restorative treatments. Hence these patients tend to attend regularly for repair and replacement of their dental restorations and fractured cusps.

D. Nasser, S. Dunne, London

DOI: 10.1038/sj.bdj.2013.385

\section{ORAL MUCOSAL PEELING}

Sir, peeling of the oral mucosa is rarely encountered in clinical practice and consequently it can cause diagnostic confusion for unfamiliar practitioners. Therefore, we would like to share an interesting case of oral mucosal peeling that we have recently encountered.

An 80-year-old Caucasian woman presented with a three-month history of asymptomatic peeling of her oral mucosa. The medical history was unremarkable and there was no history of mechanical and chemical trauma, nor any recent changes in her usual oral hygiene practices. Clinical examination showed only grey-white strips of oral epithelium sloughing from the buccal mucosae and dorsal tongue (Fig. 1, arrows). These epithelial layers sloughed spontaneously or could be peeled off easily leaving a normal tissue base with no bleeding or erosions. A clinical diagnosis of oral mucosal peeling (epitheliolysis) was made and the patient reassured and discharged.

Oral epitheliolysis (also known as shedding oral mucosa or oral mucosal peeling) is a rarely described and often unrecognised superficial desquamation of oral mucosa that may be caused by sodium lauryl sulphate (SLS) containing oral hygiene products, though some

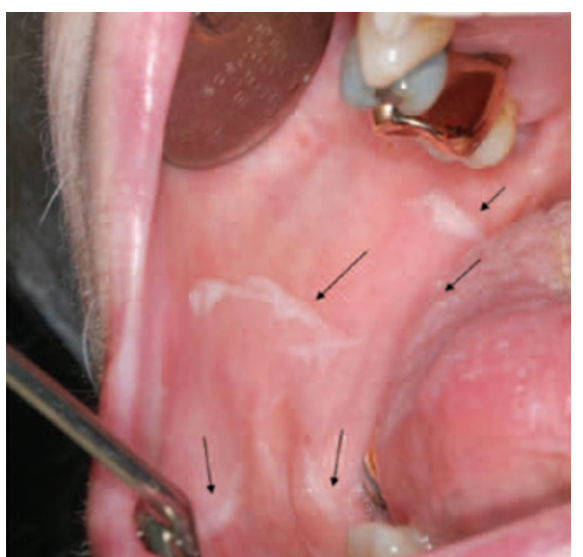

Fig. 1 Grey-white strips of oral epithelium sloughing from the buccal mucosae and dorsal tongue cases appear idiopathic. The condition has no significant clinical consequences and usually resolves spontaneously or upon discontinuation of any implicated toothpastes or mouthwashes. ${ }^{1-3}$

\section{Y. Hassona, Bristol/Jordan}

C. Scully, Bristol

1. Zegarelli D J, Silvers D N. Shedding oral mucosa Cutis 1994: 54: 323-326.

2. Herlofson B B, Barkvoll P. Oral mucosal desquamation caused by two toothpaste detergents in an experimental model. Eur J Oral Sci 1996; 104: 21-26.

3. Plonait D R, Reichart PA. Epitheliolysis of the mouth mucosa (mucosal peeling) as a side effect of toothpaste. Mund Kiefer Gesichtschir 1999; 3: 78-81.

DOI: 10.1038/sj.bdj.2013.386

\section{EVOLUTION OF A CHARITY}

Sir, I am pleased to give readers an update to my article in the $B D J$ in 2007 giving an insight into my experiences working for the Northern Cleft Foundation (NCF). ${ }^{1}$ The charity has been travelling around India for the last 13 years and has grown in size to include clinicians that normally form part of the cleft multidisciplinary team.

The fundraising for this year's trip took a slight twist on the previous five years. We developed a new website (www.northerncleftfoundation.co.uk) and also created Facebook and Twitter accounts to improve our online profile and to create awareness of the trip. International charities such as SEWA UK (www.sewauk.org) have also rallied to our cause to raise money.

I travelled with my friend and fellow registrar in oral and maxillofacial surgery, Chris Sweet, and we were overwhelmed that the team this year had grown to 48 ! This included a mix of surgical, anaesthetic, ward and specialist cleft nursing and recovery staff. When we arrived in Nagpur, the local Indian Rotary Club of Nagpur West had worked relentlessly for ten months prior to us arriving distributing leaflets in a radius of $500 \mathrm{~km}$ to recruit patients. Ten days of back-to-back operating for approximately 12 hours each day ensued under the supervision of Miss Beale and Misters Penfold, Drake, Van Eeden and Russell.

The aim of the charity has always been to provide quality, safe surgery, and not to operate on large volumes of patients at lower standards. Our final tally included 121 cases successfully treated; the youngest patient was three months of age 